10

\title{
Самоорганизующиеся субволновые периодические решетки на поверхности кварцевого стекла
}

\author{
(C) С.А. Бибичева ${ }^{1,2}$, А.Е. Рупасов ${ }^{1,3}$, П.А. Данилов ${ }^{1,3}$, А.А. Ионин ${ }^{1}$, Н.А. Смирнов ${ }^{1,3}$, С.И. Кудряшов ${ }^{1,3}$, \\ C.Н. Шелыгина ${ }^{1}$, Р.А. Заколдаев ${ }^{3}$ \\ ${ }^{1}$ Физический институт им. П.Н. Лебедева, \\ 119991 Москва, Россия \\ ${ }^{2}$ МГТУ им. Н.Э. Баумана, \\ 105005 Москва, Россия \\ ${ }^{3}$ Университет ИТМО, \\ 197101 Санкт-Петербург, Россия \\ e-mail: Sofiyabibi@mail.ru
}

Поступила в редакцию 20.12.2021 г.

В окончательной редакции 20.12.2021 г.

Принята к публикации 30.12.2021 г.

Исследовано взаимодействие фемтосекундных лазерных импульсов с поверхностью кварцевого стекла. В результате интерференции между падающим излучением и поверхностными плазмон-поляритонами наблюдалось образование самоорганизующихся субволновых периодических структур с периодом $250 \mathrm{~nm}$. Выявлена минимальная энергия в импульсе, при которой запись происходит без абляции поверхности.

Ключевые слова: прямая лазерная запись, фемтосекундные лазерные импульсы, кварц, нанорешетки.

DOI: $10.21883 /$ OS.2022.04.52272.58-21

\section{Введение}

В последние годы активно развивается область прямой лазерно-оптической записи функциональных элементов в объеме и на плоскости широкозонных диэлектриков [1]. В процессе взаимодействия лазерного импульса с материалом происходит нелинейное поглощение [2]. Как известно, для реализации нелинейного рассеяния напряженность электрического поля лазерного импульса должна быть сопоставима с напряженностью поля, связывающего электроны в атомах. Чтобы добиться такого уровня напряженности, необходима очень высокая интенсивность лазерного излучения. В зависимости от параметров излучения можно получить разные модификации в диэлектриках [3-5]: области уплотнения или разуплотнения материала, точечные дефекты и т.д. Применение лазера в обработке диэлектриков используется в таких областях, как запись волноводов [6], изготовление двулучепреломляющих элементов [7], трехмерная оптическая память [8], как голографическая запись, 5D оптическая память и 3D голографическая память $[9,10]$.

Кварцевое стекло - отличный материал для производства оптических компонентов для видимой и ближней инфракрасной (ИК) областей спектра. Их эксплуатация возможна до температуры $950^{\circ} \mathrm{C}$ при условии отсутствия термоудара [11]. Кварцевые стекла широко применяются в производстве высококачественных оптических изделий от простых линз до сложных элементов с многослойными диэлектрическими покрытиями, например светоделителей. Обладая достаточной инерт- ностью ко многим веществам, в том числе практически ко всем кислотам, кварцевые стекла также находят свое применение в агрессивной окружающей среде. Диэлектрические свойства вместе с очень большой электрической восприимчивостью и низкой теплопроводностью в широком диапазоне температур помогают использовать их в качестве термо- и электроизоляторов.

В настоящей работе рассматривается возможность создания на кварцевом стекле поверхностных дифракционных решеток с субволновым периодом при прямой фемтосекундной лазерной записи массивов микролиний.

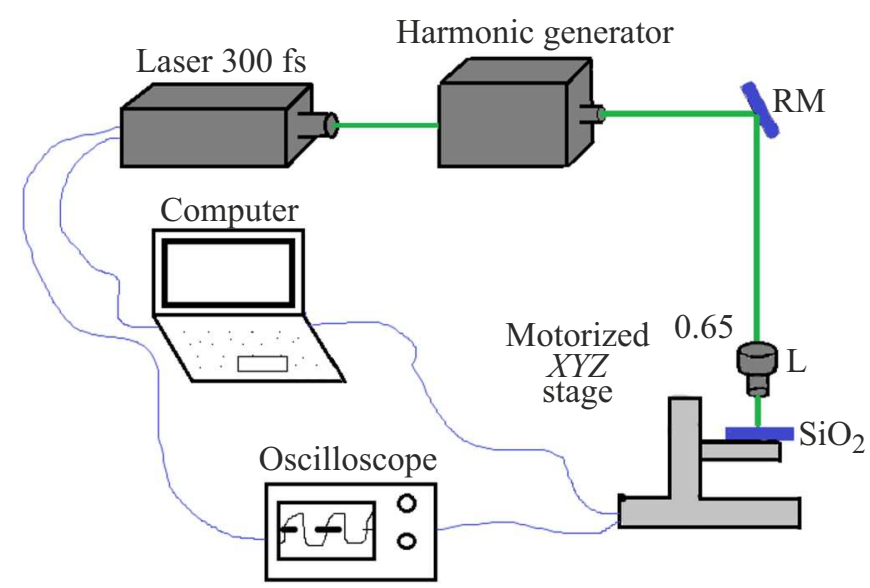

Рис. 1. Схема экспериментальной установки, использованной для записи поверхностных структур: RM - зеркала, L линза с фокусным расстоянием $200 \mathrm{~mm}$. 


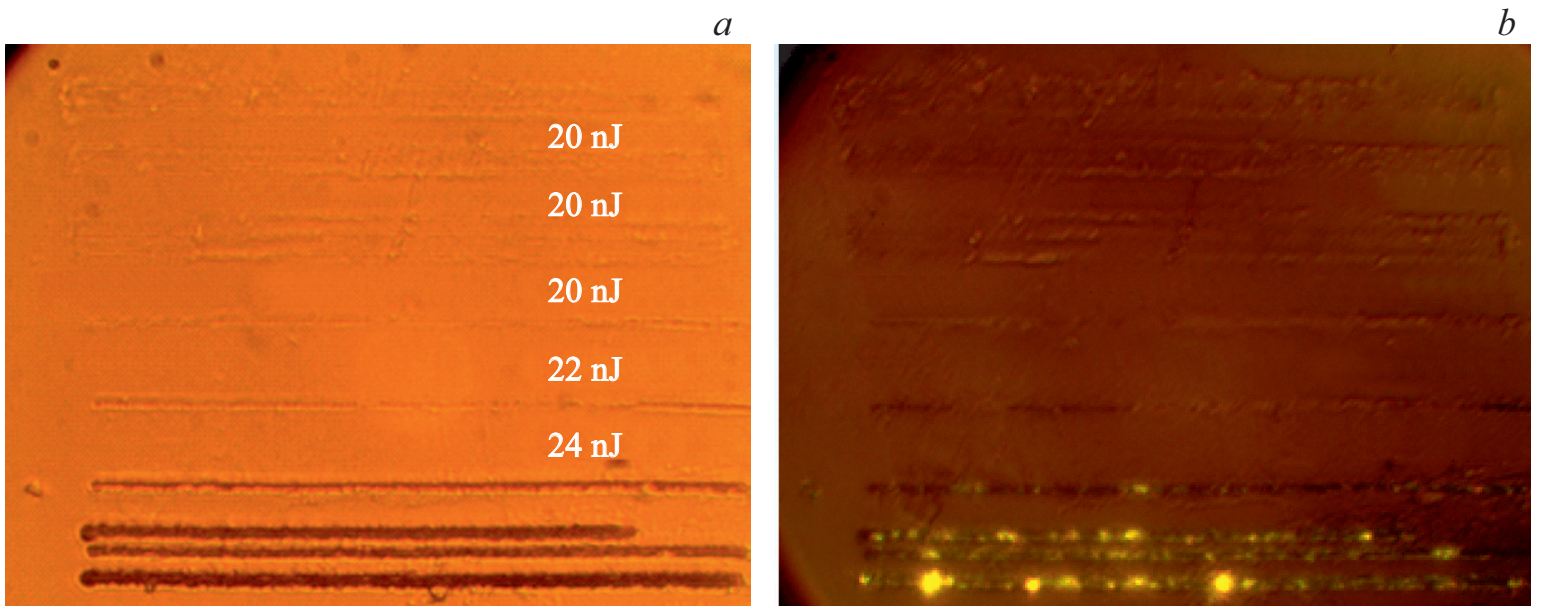

Рис. 2. Оптические изображения участка поверхности кварца с записанными линиями, полученные без поляризаторов ( $a$ ) и в скрещенных поляризаторах $(b)$. На снимках указаны значения энергии записывающих импульсов: 20, 22, 24 nJ.

$a$
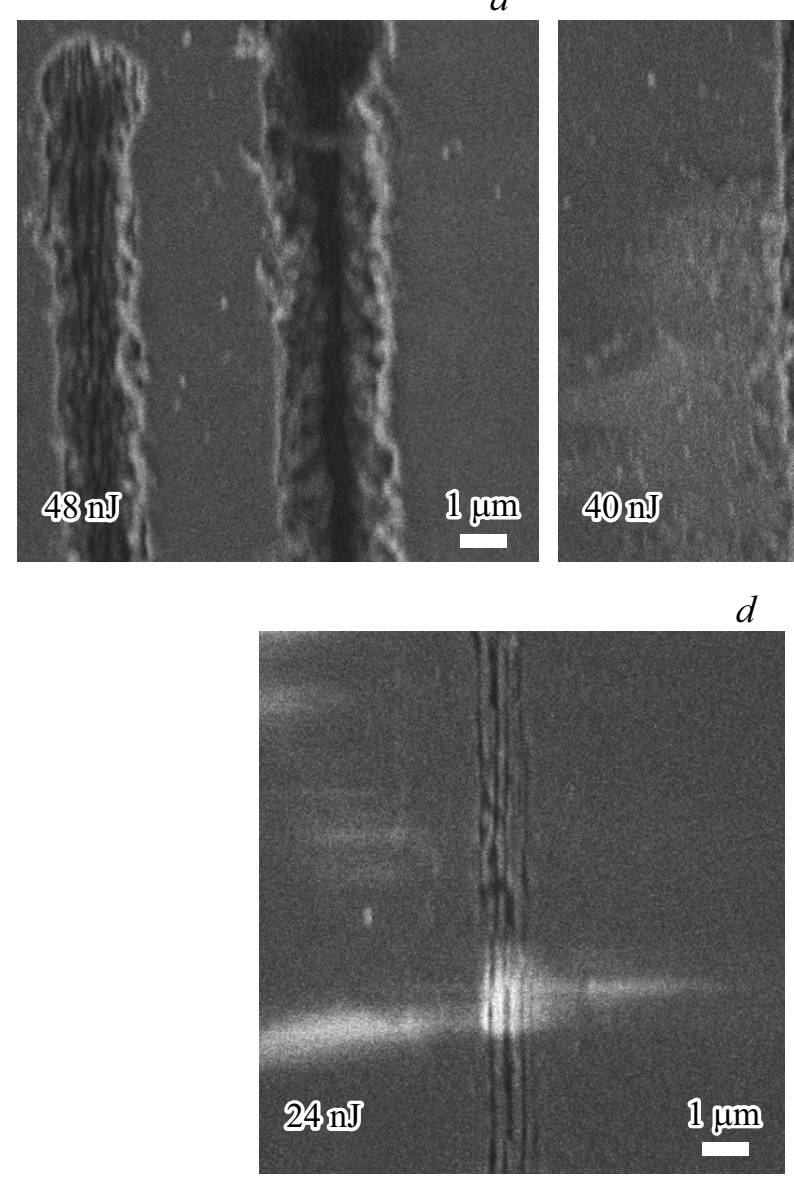

$b$

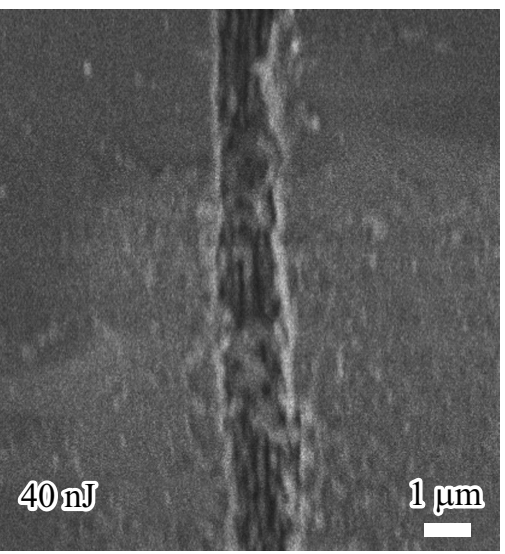

$d$

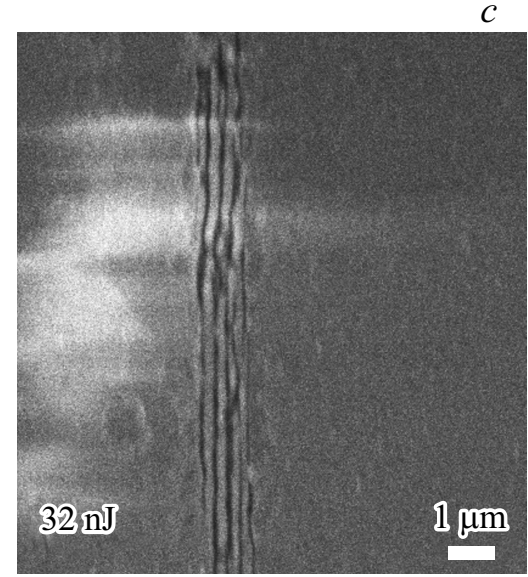

$e$

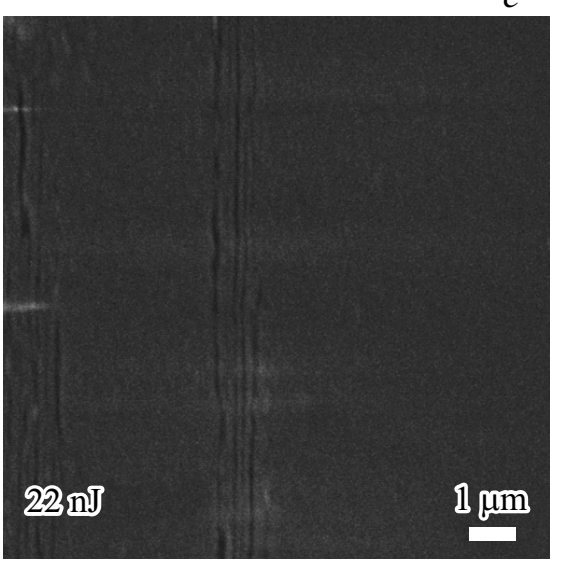

Рис. 3. СЭМ-изображения результатов записи на поверхности кварца с помощью фемтосекундного лазера при энергии импульса $48(a), 40(b), 32(c), 24(d), 22 \mathrm{~nJ}(e)$.

\section{Экспериментальные установки}

Установка, использованная для записи поверхностных структур, включает в себя генератор, многопроходный усилитель, выходной компрессор и акустооптический модулятор (рис. 1). Источником фемтосекундных лазерных импульсов была лазерная система Satsuma [12] на основе иттербиевого волоконного лазера с накачкой излучением светодиода с максимумом мощности на длине волны $850 \mathrm{~nm}$. Управление осушествляется через 
программу на внешнем компьютере. Центральная длина волны генерируемого излучения $1030 \mathrm{~nm}$, длительность импульсов $300 \mathrm{fs}$. На выходе системы максимальная энергия в импульсе может составлять до $10 \mu \mathrm{J}$.

Серии линий длиной около $200 \mu \mathrm{m}$ были записаны со скоростью $20 \mu \mathrm{m} / \mathrm{s}$ при значениях энергии импульсов $20-48 \mathrm{~nJ}$ и частоте их повторения $100 \mathrm{kHz}$. Для записи использован объектив с числовой апертурой $\mathrm{NA}=0.65$.

Для получения микромасштабного изображения поверхности использовался высоковакуумный автоэмиссионный растровый электронный микроскоп TESCAN VEGA 3 с вольфрамовым катодом.

Исследование химического и фазового составов материалов с субмикронным разрешением по площади и глубине выполнялось методом спектроскопии комбинационного рассеяния (КР) с помощью конфокального сканирующего рамановского микроскопа Confotec MR350. Поверхностные структуры были исследованы при возбуждении лазерной линией $532 \mathrm{~nm}$ пространственной области размером $1 \mu \mathrm{m}$, задаваемым числовой апертурой объектива $\mathrm{NA}=0.75$.

\section{Экспериментальные результаты и их обсуждение}

\section{Оптические снимки}

Оптические снимки записанных на поверхности кварца линий, полученные без поляризаторов и в скрещенных поляризаторах, показаны на рис. 2. При пороговой энергии записывающих импульсов $20 \mathrm{~nJ}$ образуются периодические поверхностные структуры без кратера. При энергиях импульсов, превышающих порог повреждения поверхности, происходит откольная абляция с образованием кратера и выносом частиц стекла (свечение в скрещенных поляризаторах, рис. $2, b$ ).

\section{Сканирующая электронная микроскопия}

Методами сканирующей электронной микроскопии были получены снимки неразличимых на оптических снимках периодических самоорганизующихся структур, записанных на поверхности кварца с помощью фемтосекундного лазера (рис. 3). Пространственный период этих структур составляет около $250 \mathrm{~nm}$. Их появление связано с интерференцией между падающим фемтосекундным лазерным излучением и поверхностными плазмонполяритонами $K \geq 1 / \lambda_{\text {las }}$ (решетки с околоволновыми периодами) [13,14]. Для возникновения поверхностных плазмон-поляритонов диэлектрическая проницаемость должна быть отрицательной. Поскольку при фотовозбуждении кварца происходит его металлизация, диэлектрическая проницаемость кварца становится отрицательной [15].

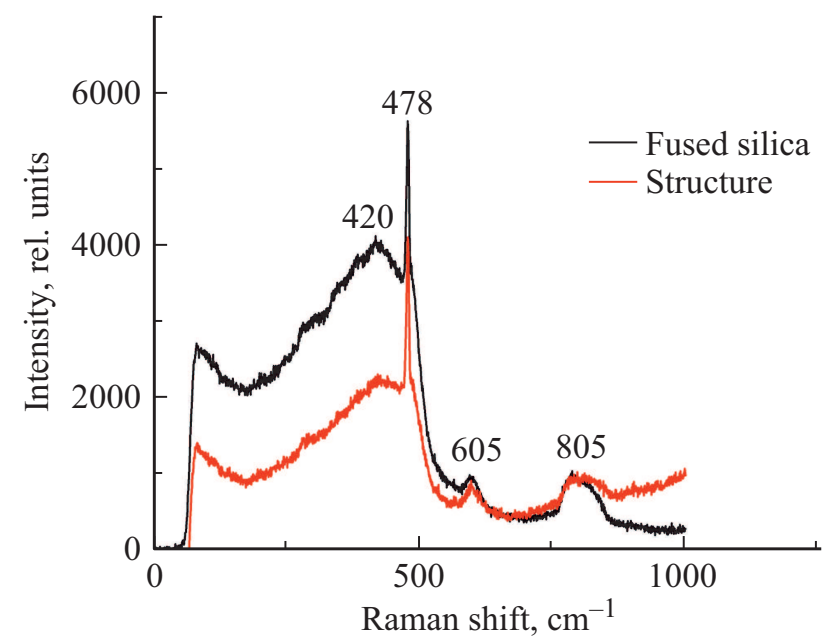

Рис. 4. Спектры КР необработанной поверхности и структуры с периодом $\sim 250 \mathrm{~nm}$, созданной импульсами с энергией $22 \mathrm{~nJ}$.

\section{Комбинационное рассеяние}

Спектроскопия КР является эффективным методом для определения структурных модификаций в стекле. Основной особенностью спектра КР кварцевого стекла является широкая полоса с центром $\sim 420 \mathrm{~cm}^{-1}$, связанная с раскачиванием и изгибом связи $\mathrm{Si}-\mathrm{O}-\mathrm{Si}$. Полосы при 478, 605 и $805 \mathrm{~cm}^{-1}$ отражают колебательные движения атомов кислорода в четырех- и трехчленных кольцевых структурах [16].

Для оценки модификаций в стекле после фемтосекундной лазерной обработки было выполнено КРсканирование в области поверхностных структур. Полоса $478 \mathrm{~cm}^{-1}$ относится к трехчленным кольцевым связям в решетке кварца (рис. 3). Изменение в соотношении между амплитудами пиков на 420 и $478 \mathrm{~cm}^{-1}$ можно связать с фотоиндуцированными разрывами напряженных мостиковых связей $\mathrm{Si}-\mathrm{O}-\mathrm{Si}$.

\section{Заключение}

В этой работе мы продемонстрировали возможность создания самоорганизующихся структур с субволновым периодом на поверхности кварца при фемтосекудной лазерной обработке. Период получаемых субмикронных структур составил порядка $250 \mathrm{~nm}$. В работе были определены пороговые режимы структурирования поверхности кварцевого стекла, при которых не происходит откольная абляция. Исходя из результатов спектроскопии КР можно сделать выводы об изменении концентрации кольцевых связей кислорода в кварце и области модификации.

\section{Финансирование работы}

Исследование выполнено за счет гранта Российского научного фонда (проект № 20-71-10103). 


\section{Конфликт интересов}

Авторы заявляют, что у них нет конфликта интересов.

\section{Список литературы}

[1] R. Woods-Robinson, Y. Han, H. Zhang, T. Ablekim, I. Khan, K.A. Persson, A. Zakutayev. Chem. Rev., 120 (9), 4007-4055 (2020). DOI: 10.1021/acs.chemrev.9b00600

[2] D.V. Kartashov, A.V. Kirsanov, A.M. Kiselev, A.N. Stepanov, N.N. Bochkarev, Yu.N. Ponomarev, B.A. Tikhomirov. Opt. Exp., 14 (17), 7552-7558 (2006). DOI: 10.1364/OE.14.007552

[3] N. Sanner, O. Utéza, B. Bussiere, G. Coustillier, A. Leray, T. Itina, M. Sentis. Appl. Phys. A, 94 (4), 889-897 (2009) DOI: $10.1007 / \mathrm{s} 00339-009-5077-6$

[4] K.I. Popov, C. McElcheran, K. Briggs, S. Mack, L. Ramunno. Opt. Exp., 19 (1), 271-282 (2011). DOI: $10.1364 / O E .19 .000271$

[5] S. Gräf Clemens, K. Frank, A. Müller. Materials, 10 (8), 933 (2017). DOI: 10.3390/ma10080933

[6] A.A. Khalil, P. Lalanne, J.-P. Berube, Y. Petit, R. Vallee, L. Canioni. Opt. Exp., 27 (22), 31130-31143 (2019). DOI: 10.1364/OE.27.031130

[7] S.S. Fedotov, A.G. Okhrimchuk, A.S. Lipatiev, A.A. Stepko, K.I. Piyanzina, G.Yu. Shakhgildyan, M.Yu. Presniakov, I.S. Glebov, S.V. Lotarev, V.N. Sigaev. Opt. Lett., 43 (4), 851-854 (2018). DOI: 10.1364/OL.43.000851

[8] K. Miura, J. Qiu, S. Fujiwara, S. Sakaguchi, K. Hirao. Appl. Phys. Lett., 80 (13), (2002).

[9] B. Eggleton, B. Luther-Davies, K.N. Richardson. Nat. Photon., $5(3), 141-148$ (2011).

[10] F. Brückerhoff-Plückelmann, J. Feldmann, C.D. Wright, H. Bhaskaran, W.H. Pernice. J. Appl. Phys., 129 (15), 151103 (2021). DOI: $10.1063 / 5.0042549$

[11] A.P. Velmuzhov, M.V. Sukhanov, M.F. Churbanov, T.V. Kotereva. Inorg. Mat., 54 (9), 925-930 (2018).

[12] A.E. Rupasov, P.A. Danilov, M.P. Smaev, M.S. Kovalev, A.S. Zolot'ko, A.A. Ionin, S.I. Kudryashov. Opt. Spectrosc., 128 (7), 928-931 (2020) DOI: $10.1134 / \mathrm{S} 0030400 \mathrm{X} 20070188$

[13] J. Wu, Y. Zhang, L.QiLi, Y. Ren, Q. Lu, L. Wand, F. Chen. Results in Physics, 21, 103814 (2021). DOI: $10.1016 /$ j.rinp.2021.103814

[14] S. Kudryashov, A. Levchenko, P.A. Danilov, N. Smirnov, A.A. Rudenko, N. Melnik, N. Busleev, A.A. Ionin. Appl. Phys. Lett., 115 (7), 073102 (2019). DOI: 10.1063/1.5114630

[15] P.A. Danilov, S.I. Kudryashov, A.E. Rupasov, N.A. Smirnov, E. A. Oleynichuk , A.S. Rivnyukc, R.A. Zakoldaev. JETP Lett., 113 (10), 622-625 (2021). DOI: $10.1134 / \mathrm{S} 0021364021100052$

[16] S.O. Kucheyev, S.G. Demos. Appl. Phys. Lett., 82 (26), 3230 (2003). 